\title{
() ENSINO DA FILOSOFIA DA \\ EDUCAÇÃO NO CURSO \\ DE PEDAGOGIA
}

\section{Ivanilde Apoluceno de OLIVEIRA \\ Universidade do Estado do Pará}

Resumo: Este texto apresenta algumas reflexöes sobre o ensino da Filosofia da Educação no Curso de Pedagogia. O foco de debate é a reformulação curricular, cuja tendência generalista secundariza as disciplinas de fundanentos como a Fïlosofia da Educação em favor das disciplinas técnico-pedagógicas. Essa situação influencia negativamente na qualidade do ensino da Filosofia da Educação, interferindo também na formaçāo do educador:

\section{A crise do Curso de Pedagogia}

Nos Cursos de Pedagogia, constata-se uma crise configurada pela 1 «ssivel perda de sua funçāo em preparar pedagogicamente para a docência uu nível médio, na educaçāo infantil e nas primeiras séries do ensino Iıudamental. A formação de profissionais de educação para administração, upervisão, etc., tenderia, também, a desaparecer ao ser oferccida essa I. rmação na pós-graduação ou em treinamento em serviço.

O que ocasiona essa situaçāo de crise é a criação pela nova LDB (Artigos 62, 63 e 64), dos Institutos Superiores de Educação c do Curso Normal Superior, bem como o fato de ser a pós-graduaçüo fixadia como . Iternativa de formação dos profissionais de educaçãos.

Além disso, as Diretrizes Curriculares dirccionan o foco da formação do pedagogo para o currículo (uso das diretrizes curriculares como referência de qualidade), secundarizando tanto o espaşo da formação (Universidade ou Institutos Superiores de Educaçăo) como o neme do curso (Pedagogia ou Curso Normal Superior).

As diretrizes curriculares, então, sāo apresentadas como oricntadoras da formação de docentes, isto é, como um "conjunto de princípios, fundamentos e procedimentos a serem obscrvados na organizaçāo institucional e curricular de cada estabelecimento de cusino c aplicam-se a todas as etapas e modalidades da educação básica"!

\footnotetext{
Resolução CNE/CP1/2002 - Diretrizes Curriculares para a formaşio de protessores da vducação básica, píg. 01.
} 
A hevencia curricular comum a todos os cursos de formação, .11 wes dis diretrizes curriculares, é justificada pelo MEC, por fortalecer 1) "unuliule nacional" (meio de integração), sem deixar de referir-se à Ih siluludade como estratégia de autonomia das Instituiçōes de Ensino. lintretanto, a autonomia, neste contexto, reduz-se à escolha oụ seleção ulus princípios, fundamentos e procedimentos previamente indicados pulas dirctrizes curriculares.

() Curso de Pedagogia, então, constitui-se em um tema polêmico, ustando no centro de debates dos educadores em diversos fóruns e cutidades representativas da área da educação, como a ANFOPE, a ANPED, a Comissāo de Especialistas de Ensino de Pedagogia, entre outros.

A posição dessas entidades é a de que a Universidade e o Curso de Pedagogia constitui o locus de formaçẫo de profissionais em educação, scndo a docencia a base do curso.

A docência é considerada o elemento articulador entre os pedagogos c os licenciados das diversas áreas de conhecimentos específicos, além de conferir organicidade aos diferentes níveis do trabalho pedagógico (educaçāo infantil, fundamental e médio, jovens e adultos, etc.) e às tarefas de organização e gestão dos espaços escolares, formulaçāo de políticas educacionais, planejamento, etc. (SCHEIBE, 2000).

Nesta perspectiva, o pedagogo poderá atuar:

na docência na educaçāo infantil, nas séries iniciais do ensino fundanental e nas disciplinas de formaçāo pedagógica do nivel médio. E, ainda: na organização de sistemas, unidades, projetos e experiências edncacionais escolares e nāo escolares; na produção e difusāo do conhecimento científico e tecnológico do campo educacional; nas áreas emergentes do campo educacional (SCHEIBE, 2000, p.13).

Assim, esses foruns apresentam como amplas as possibilidades de atuaçiono do pedagogo, por terem como base a docência, sendo tarefa dos projetos pedagógicos dos Cursos de Pedagogia a definição dos seus a 111 pos de atuação.

O campo de atıação profissional dos licenciados em pedagogia "näo poderia, portanto, deixar de ser, privilegiadamente, o próprio magistério e as diversas especificidades que este 
magistério enseja para a sua plena realizaşão, seja na ednas̆ão de adultos, no atendimento às necessidades especiais, na supervisāo das atividades escolares, etc. Sna atuação, no entanto, também é desejável em atividades não escolares, onde o domínio profissional do ato educativo intencional se fizer necessário. Esta atuaģão tem como fonte de formaçāo as mesmas bases presentes na formação do pedagogo escolar (SAVIANI apud SCHEIBE, 2000, p.16).

Neste sentido, as modalidades de ensino, como a educação de fuv. 11: " adultos e a educação especial assim como as instituiçōes (1) 1 แ! irias, são consideradas campos de formaçāo e de atuação do

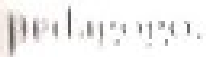

\section{A Reformulação Curricular e o Ensino da Filosofia da Educação}

I mu lunçāo dessa situação de crise, os Cursos de Pedagogia vêm nen.1. 1 undificados, e os novos projetos pedagógicos vêm se apresentando 411 1111.t estrutura generalista, eliminando-se as habilitações (Supervisāo, Aiłum stação e Orientação Educacional).

A wondência de formação generalista apresentada nos Cursos de Pullı! m! tem se constituído, na prática, em uma estrutura curricular frapun ut.kla, estando as disciplinas distribuídas de forma representativa por + rul. campo de atuação do pedagogo. Assim, representando cada

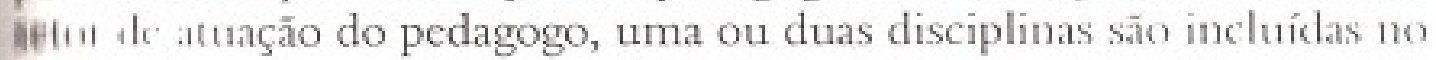
furı ulu: sobre gestão, planejamento, avaliação, educaçăo especial,

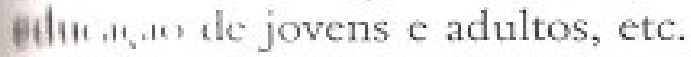

^ prexucupação não é com os fins da educação, c sim com a scleçāo Han ilse plinas consideradas significativas para formar tecnicamente o pholesest para atuar nas diversas áreas profissionais da Pedaģogria.

Nest: rede de disciplinas, o caráter técnico predomina. As clisciplinas He Iuncluncntos, como a Introdução à Filosofia, Introdução ì Sociologia

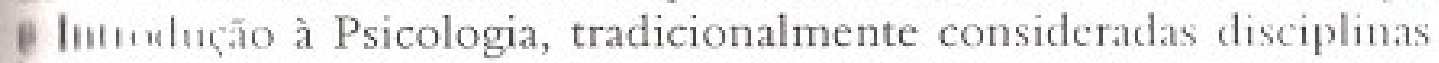
bahm ، ا.ı P'edagogia, não estão sendo incluídas no currículo. Com isso, per excmplo, cabc à disciplina Filosofia da Educação a responsabilidade He 11,1 ualluar com o conteúdo da Introdução à Filosofia.

Aurcsenta-se of fato de que a Filosofia da Educação, que geralmente tri uletrcida no segundo e/ou terceiro anos, com essa nova situação, piansiा a ser ofertada no primeiro ano. 
Alyuns cursos ainda ofertam a Filosofia da Educação I e II, mas

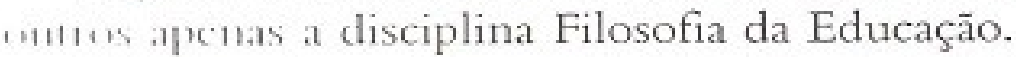

() S deccntes então que atuam com a Filosofia da Educação, vêm cufrentando algumas dificuldades ao receber o aluno, no primeiro ano, s'mil as bases filosóficas da Introdução à Filosofia:

1) Nāo conseguem trabalhar de forma aprofundada nem o conteúdo da Introdução à Filosofia nem o da Filosofia da Educação;

2) Ou se detém mais no conteúdo introdutório da filosofia ou se detém mais na educação;

3) Não concluem o programa estabelecido. A tendência é de reduçāo do conteúdo programático, em função das dificuldades dos alunos em aprofundar as leituras filosóficas sobre a educação.

Alguns professores dividem o conteúdo da disciplina em duas partes: a primeira com conteúdo da Introdução ou História da Filosofia e a segunda parte com a Filosofia da Educaçāo. Outros, procuram articular os conteúdos filosóficos e os educacionais a partir de eixos temáticos, debatendo após o estudo filosófico sobre o tema as questōes educacionais.

A meu ver, essa articulação é fundamental para a Filosofia da Educaçāo, mas o problema que se esbarra no ensino desta disciplina é a redução da carga horária para aprofundamento das leituras filosóficas necessárias à análise crítica sobre a educação, com a retirada do currículo da disciplina introdutória de filosofia. A carga horária da Introdução a Filosofia não foi deslocada para a Filosofia da Educaçāo.

Com essa situação, o ensino da Filosofia da Educação não tem dado conta de trabalhar o referencial filosófico necessário para instrumentalização da leitura e análise da educação. Os docentes têm de priorizar o estudo da filosofia para alguns eixos de reflexão: o histórico ou o epistemológico ou o antropológico ou o ético, etc.

Desta forma, não conseguem ampliar o debate sobre algumas questöes filosóficas fundamentais para a educação como é o caso da lógica, da ideologia c da ética, por exemplo. Não conseguem, também, desenvolver a pesquisa de campo e a pesquisa bibliográfica fica comprometida. Apesar das leituras indicadas, os alunos encontram dificuldades na compreensão e no debate dos textos filosóficos em classe.

OLIVEIRA explica que:

Se "todos são filósofos" como afirma Gramsci, e se homens mulheres procuram refletir sobre os problemas que a realidade apresenta, o que leva os educadores e os educandos, enquanto 
filósofos da educação, a filosofarem são os problemas que encontram a realizarem a açāo educativa. Estas questóes de ordem pedagógica revertem-se em interrogaçōes de caráter filosófico por buscarem a razāo de ser do fenômeno educativo e de sua práxis educativa apresentando implicitamente questōes e explicaşóes sobre a natureza do ser humano e do mundo. Subjacente a uma concepşāo de educą̧ão e a uma prática pedagógica está presente unu teoria sobre o ser humano e sua relação com o mundo. É importante desta forma que o educador, enquanto filósofo da educaşão, reflita sobre a problemática educacional na busca de um significado existencial e político para a sua prática educativa (2003, p. 41).

Essa tarefa da Filosofia da Educação de possibilitar ao discente a m. ilise dos discursos educacionais, a problematização ética e política ‘.ı práticas educacionais, vem sendo obstaculizada por essa fragmentaçāo 1 urricular.

Os discentes têm dificuldade em analisar os problemas educacionais I" ir falta de embasamento teórico, porque se encontram, ainda, na fase ke apropriação dos conceitos filosóficos, tentando compreender e ssimilar o que é a própria filosofia, sua finalidade, especificidade, etc. relucativa:

Cabe ao edncador questionar permanentemente sobre o objetivo do sen trabalho, sobre os sujeitos de sua prática, sobre o scuido dos procedinentos que ntiliza, sobre o que ci conhecimento, sobre efetividade, sobre métodos, sobre os contcridos qute vicula, e tantos outros objetos que estäo conpronetides com sta prática. Os objetos de meditação filoséfica para o educuder nāo cstão distantes de suas condutas; não sāo objetes abstrutos. Ao contrário, sāo os fenômenos, acontecimculos c fatos que estão imediatamente juntos de si, diretamente articulados com a materialidade de sua ação. A filosofia e o excricio do filosofar têm consequiências diretas e imcdiatas para a nossa prática educativa, na medida em que atuam buscando e produzindo fundamentos que dêem direção ao nosso agir. Aliás, como sudo o mais na vida humana, também na prática educativa nāo se age sem filosofia $(1990, \mathrm{p} .43)$. 
(1) cusıu da Filosofia da Educação requer não apenas estudos sobre - Lustiria da filosofia, das concepçôes de mundo produzidas husturicancutc; mas também, a reflexāo sobre os problemas viveruciados pelos indivíduos na sociedade e na educação. "Na relação dialetica cntre a compreensão do produzido historicamente e o refletido no contexto educacional atual é que o educador busca sentido - ¿lireciona sua prática educativas (OLIVEIRA, 2003, p. 41).

E justamente esse tempo de reflexão filosófica sobre a história e o vivenciado no cotidiano pelos alunos que está sendo obstaculizado no cnsino atual da Filosofia da Educação.

Além disso, o tempo necessário de apreensāo dos conceitos estão sendo encurtados ao serem alguns Cursos de Pedagogia deslocados da oferta anual para a semestral. Intensifica-se o número de aulas semanais, mas não há tempo para leitura e reflexāo do lido.

Acrescenta-se o fato de que a fragmentação nas outras disciplinas de fundamentos, como a sociologia e a psicologia, auxiliam a agravar o quadro de formação do educador. Há uma ausência no vocabulário dos discentes dos conceitos básicos destas disciplinas.

Desta forma, a secundarização das disciplinas de fundamentos em relação às técnicas vem agravando a crise do curso e refletindo de forma preocupante na qualidade da formação dos pedagogos. A formação generalista que deveria possibilitar ao aluno de Pedagogia uma visão mais ampla da educaçāo, ao ser adotada numa perspectiva tecnicista, pulveriza o conhecimento, fragmenta o olhar e impede a reflexão crítica.

\section{Formaçāo Generalista Crítica x a Tecnicista}

Ao meu ver a questão não está na construção do Currícule Generalista e sim na tendência tecnicista que o Curso de Pedagogì cstá mais uma vez incorporando em seu currículo.

Essa ausência do debate filosófico no Curso de Pedagogia ge apresenta inclusive na formação do seu currículo. A escolha di disciplinas técnico-pedagógicas em detrimento das disciplinas de fundamentos está pautada em que concepção de ser humano? Questác antropológica filosófica necessária a qualquer projeto polítice pedaýgico.

Essa tendência tecnicista é uma opção dos educadores ou uprexlusiou de um modelo que está sendo imposto por políticas oficial 
A preocupação é com as consequiências na formação do educador. A unssa experiência, nos anos 60 a 70 , de formação tecnicista no Curso 4. Pedagogia foi amplamente discutida e refutada pelos educadores p lo seu caráter reprodutivista e não crítico.

"Será que a adoção de uma determinada metoxdolog̨̣ia não implica 1.in conhecimento de psicologia e filosofia da cduciçu? Será que o uctodo deixou de ser um meio para tornar-se un fin cun si nesmo?" (\$ILVA, 1979, p. 18). Essas entre outras questöes cram problembatizadas p'los educadores, chamando a atenção para a importânc i. diss disciplinas 4k. fundamentos na formação do educador.

Diferentemente do que está ocorrendo, comsideramus que a .mpliação da atuação do Pedagogo requer um currículu coun naior fındamentação filosófica no âmbito da antropologìi, diı cpistemolong̣ia, ‘i lógica e da ética.

Ao nosso ver, as disciplinas de fundamentos e que pussibilitam uma visão ampla do processo educacional, articulandes is dilerentes ıcóes dos profissionais da educação, as políticas e as pritu as colucativas.

Assim, a construção de um currículo generalista que articule a lormação geral e a específica pode ser implementuda un (ursos de P'edagogia, mas o importante é a sua abordagem critica, scoulon t liflusotia ı 1 m dos eixos de construção dessa criticidade.

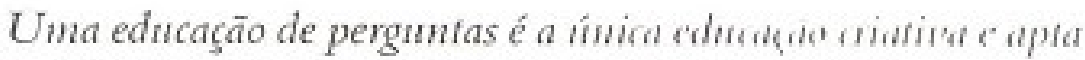
a estinular a capacidade humana de assombrar-se, de responder a seu assombro e resolver scus unchadeiros problemas essenciais, existenciais. E o própro conho' imruk (I IRLIIRE \& FAUNDEZ, 1985, p. 52).

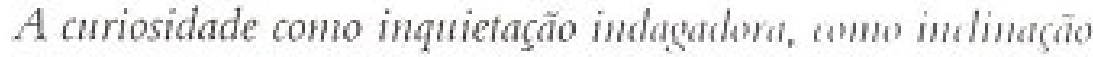
ao desvelamento de algo, como pergunla verbuli ‘ala on näo, como procura do esclarecimento, como sinal de atcuñŭo que stıgere alerta faz parte integrante do fenômcho vitul. Näo haverá criticidade sem a curiosidade que nos pōe pacienténente impacientes diante do mundo que nāo fizcmos, acrscentando algo a ele que fazemos (FREIRE, 1997, p. 35).

A filosofia, além da base de compreensẫo da príxis educacional, tem que se constituir em ferramenta para leitura dos textos $\mathrm{cm}$ educação c essa tarefa exige um tempo para que o aluno se apropric dos conceitos, 


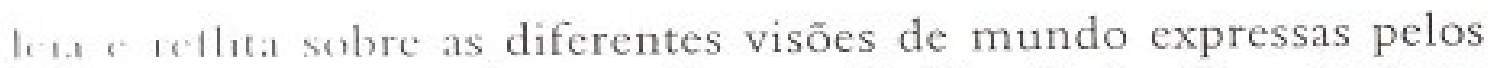

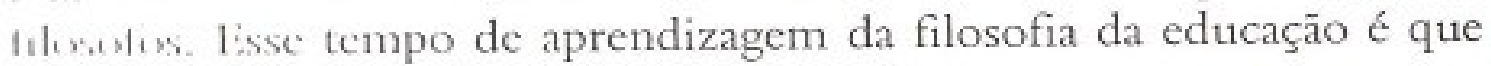
fur isa ser repensada na formaçāo do pedagogo.

(1) exercício de pensar o tempo, de pensar a técnica, de pensar o unlecimento enquanto se conhece, de pensar o quê das coisas, o para uluć, o como, o em favor de quê, de quem, o contra quê, o contra ' fuc!u, săo exigências fundamentais de uma educação democrática à alura dos desafios do nosso tempo (FREIRE, 2000, p. 102).

Para isso, o próprio ensino da Filosofia da Educaçāo precisa ser discutido nos Cursos de Pedagogia e nos Fóruns de debate sobre o tema.

A disciplina Filosofia da Educação está presente na crise do Curso de Pedagogia e precisa ser discutida como tal. É um debate que envolve a reflexão sobre a política nacional de educação e a formaçāo do Pedagogo, pautada em questôes filosóficas, tais como: Que pedagogos queremos formar? Que sociedade precisamos construir? Esse é um debate que os professores de Filosofia da Educação não podem deixar de enfrentar.

\section{Consideraçôes Finais}

A crise do Curso de Pedagogia em termos de definição da formação do pedagogo e seu campo de atuaçāo profissional vem impulsionando reformulaçōes curriculares de tendência generalista.

Mas a superação das habilitaçōes tem se dimensionado por um caráter tecnicista ao serem privilegiadas as disciplinas técnicopedagógicas em detrimento das disciplinas de fundamentos, o que tem influenciado de forma negativa no ensino da filosofia da educação e na formação do educador.

A crise no Curso de Pedagogia se constitui, também, na crise do ensino da Filosofia da Educação. Isto significa que a criticidade necessária ì formação do educador trabalhada pela Filosofia da Educação nāo está sendo reconhecida pelos educadores. Neste sentido, ela não estí conseguindo, na prática, evidenciar a sua relevância na formação do educador.

Além disso, o debate sobre a redução das disciplinas filosóficas introdutórias não pode ser considerado como uma questão de corpurativismo, e sim como necessária à própria compreensão de alucaçono, na medida em que a práxis educativa tem subjacente uma visão lilosófica de ser humano e de mundo. 
Assim, os professores de Filosofia da Educação precisam discutir 11.. ( ' irso de Pedagogia não só a relevância das disciplinas filosóficas, 111... sobrctudo o seu próprio ensino, se está cumprindo a tarefa de finsulitar aos educadores, em sua formação, a reflexão crítica sobre 104 pithlemas educacionais.

\section{IIBLIOGRAFIA}

BuA 11 . Diretrizes Curriculares Nacionais para a Formaģăo de Professores da Eidhu,(ti) Básica. Resoluçāo CNE/CP1/2002. Brasília: MEC, 2002.

PIII IRI: Paulo. Pedagogia da Indignaşão: cartas pedagógicas c outros Enutu, Sīo Paulo: UNESP, 2000.

Pedagogia da Autonomia: saberes necessários à prática educativa. 6) inl Siss Paulo: Paz e Terra, 1997.

$\therefore$ FAUNDEZ, Antonio. Por uma pedagogia da pergunta. Rio de Jinew.. P.x. e Terra, 1985.

UUT KI:SI, Cipriano. Filosofia, exercício do filosofar e prática educativa. Iini whrok. IX (45), Brasília: INEP, Jan/Mar, 1990.

OLIVI:IRA, Ivanilde Apoluceno. Filosofia da Educaşão: reflexōes e debates. Peil. Him: UNAMA, 2003.

CIIIIIt1: Leda. Formação e identidade do pedagogo no Brasil. In: Iinsimu " "iprender: sujeitos, saberes e pesquisa. Rio de Janeiro: DP\&A, 2000.

IIIVA. Irequiel Theodoro. Os (Des)caminhos da escola: trammatismo Cllichiomair São Paulo: Cortez \& Moraes, 1979.

Artigo recebido no dia 20 de dezembro de 2004 e aprovado no dia 28 de abril de 2005. 